\title{
Assessing the role of thermal erosion in channel deformation processes in rivers of permafrost zone
}

\author{
Elena Debolskaya ${ }^{1,2}$, Oksana Maslikova ${ }^{1}$, and Ilya Gritsuk $^{1,3}$ \\ ${ }^{1}$ Water Problems Institute, Russian Academy of Sciences, Gubkina 3, Moscow, 119333 Russia \\ ${ }^{2}$ Moscow State University of Civil Engineering, Yaroslavskoye Shosse 26, Moscow, 129337 Russia \\ ${ }^{3}$ RUDN University, Miklukho-Maklaya, 6, Moscow, 117198 Russia
}

\begin{abstract}
Thestudy is focused on the deformations caused by the impact of water flow in a river channel composed of melt-able permafrost rocks. It is based on the results of laboratory and mathematical simulation. The results of numerical calculations are compared with data of laboratory and field observations. The study shows that a comprehensive and adequate model of river channel deformations should take into account not only ablation, but also other factors, including heat transfer in the soil, sediment transport, and bank slope collapses. Numerical experiments with an improved mathematical model, applied to long time intervals, have shown that the differences between the averaged deformations, calculated by a model of ablation alone, i.e., ignoring bank slope collapses and sediment transport, and a comprehensive model can be considerable. Experiments in a hydraulic flume were good enough to reproduce the effect of delayed collapse, consisting in nonsimultaneous impacts of channel-forming rock melting and a freshet.
\end{abstract}

\section{Introduction}

The major two differences between channel deformation processes in rivers in permafrost zone and beyond it are due to the considerable effect of thermal erosion and the nonsimultaneous effects of the melting of channel-forming rocks and flood wave. Laboratory experiments [1] and field observations [2] have shown that the role of thermal erosion in the deformation of channels in permafrost rocks is considerable and, sometimes, even greater than that of mechanical erosion. However, the second factor that distinguishes river channel deformations in permafrost zone from those in moderate-climate areas is the time lag between the manifestation of maximal erosion activity and flood peak; this factor questions both the opinion that the presence of permafrost accelerates deformation processes and the opposite opinion. As mentioned in [3, 4], soil freezing reduces the erosion activity in the period of snow melting and the passage of spring flood wave. However, freshets are accompanied by more active erosion, which is facilitated by the

* Corresponding author: oksana68@mail.ru 
gradual thawing of permafrost soils in summer and their total saturation because of the effect of an aquiclude, i.e., the roof of permafrost rocks. Tananaev et al. [3, 4] believe that the sediment loads during freshets in warm seasons, even at lower water discharges, can be far in excess of their values during spring floods. Clearly, in addition to the thermal effects, which manifest themselves as thawing of frozen channel-forming rocks, the sediment transport, solifluction, and collapses also contribute much to the erosion processes in arctic rivers. The objective of the study is to assess the role of the latter processes, i.e., to reveal the significance of each factor that governs thermal erosion.

\section{Laboratory modeling}

The laboratory experiment was carried out in a close-cycle flume $4 \mathrm{~m}$ in length, 0.25 to $1 \mathrm{~m}$ in width, and $0.15 \mathrm{~m}$ in depth. Water temperature was kept constant during each experiment. The bed slopes consisted of graded river sand with particle size up to $0.001 \mathrm{~m}$. The cross-section of the simulated channel was trapezoidal with lateral slopes varying in individual experiments. Samples of frozen mixture of sand and water with specified ice content or pure-ice samples were placed in a side of the flume (Fig. 1b). The flow velocity varied depending on water flow rate, flume bed slope, or cross-section in each experiment. The most vivid results were obtained in a laboratory experiment with flume bed width of $0.15 \mathrm{~m}$ and depth of $0.1 \mathrm{~m}$ at the slope of the side wall with frozen sample $\alpha=30^{\circ}$ and water flow rate of $5.8 \mathrm{~L} / \mathrm{s}$. The samples of frozen sand or ice had the form of plates with dimensions varying slightly from one experiment to another. On the average, the plates were 25 in length, 15 in width, and $3 \mathrm{~cm}$ in thickness. The frozen samples were weighed and measured before and after the experiment. The change in sample weight per unit time was taken as the characteristic of the deformation dynamics of the frozen sample. Numerous studies [5-10] have shown that the major factors that have an effect on the deformations caused by thermal erosion are water and soil temperature, soil ice content, and water flow velocity. The latter parameter was the only one that could be varied within acceptable limits in the laboratory experiments; the soil ice content was represented by two values---1 for pure ice and 0.2 for frozen sand. The temperatures of water and the surrounding soil varied depending on the weather conditions; they were taken into account as corrections to other relationships. Fig. 1 gives the change of the weight of the sample of (a) pure ice and (b) frozen sand per unit time versus the mean water flow velocity.

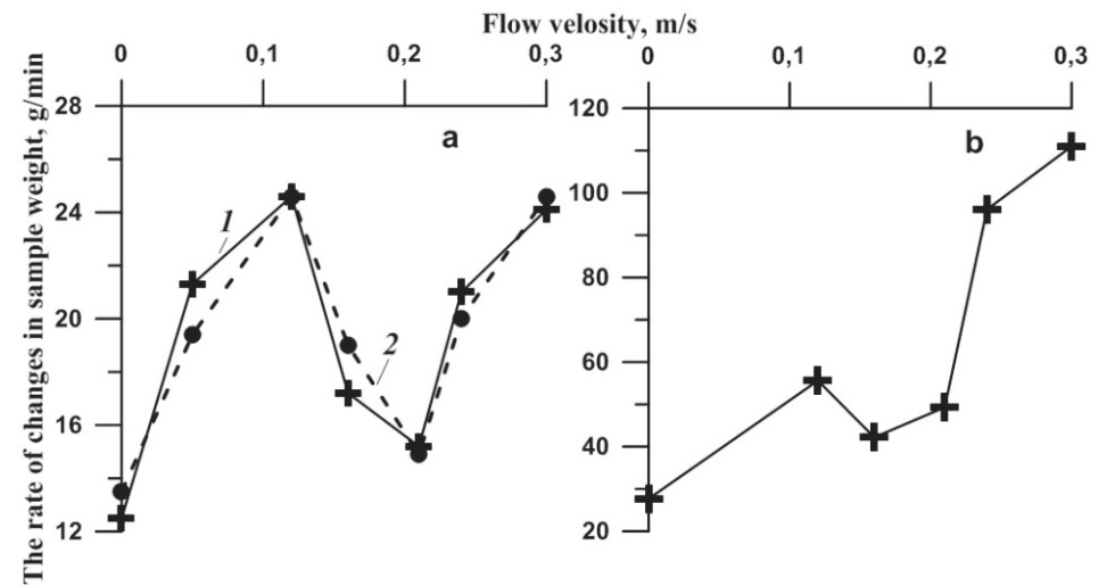

Fig. 1. Changes in the weight of (a) the sample of pure ice and (b) frozen sand per unit time versus the average velocity of the water flow: (1) measurement data, (2) numerical experiment results. 
Fig. 1a also gives the results of numerical experiments with an updated mathematical model, which has been developed by the authors earlier [11, 12]. These results will be described in greater detail further below. As can be seen from the plot, pure-ice inclusions, first, show lesser effect of the flow than the samples with lesser ice content do, other conditions remaining the same, thus supporting the conclusions made in [13-14], and, second, the changes in their weight are less dependent on water flow velocity.

The following experiment was carried out to study the nonsimultaneous effect of the thawing of channel-forming rocks and a freshet. An ice plate was placed for $12 \mathrm{~h}$ into the bank slope composed of wet sand with a positive temperature. The level of water flow all over this period was kept below the lower surface of the plate. A niche has formed in the volume previously occupied by the ice, and the walls of this niche collapsed after the starting of pumps and the formation of a wave to simulate a freshet. This effect, consisting in a time lag between the thawing of a frozen inclusion and the mechanical impact of water flow, i.e., a time shift in two mechanisms of thermal erosion process, can be referred to as an effect of delayed collapse.

One more experiment was carried out to verify the mathematical model. In this experiment, an ice bar was placed into the bank slope of a water flow $11 \mathrm{~cm}$ in depth at an average velocity of $0.24 \mathrm{~m} / \mathrm{s}$. Once the bar had melted completely, the water pumps were switched off; the channel became free of water, and a niche formed at the place of the bar; the dimensions of the niche coincided with those predicted by the model up to measurement errors. The thawing times in the laboratory and numerical experiments also coincided. Fig. 2 gives a photo of the channel, drained at the end of the experiment, and its surface calculate by the model.

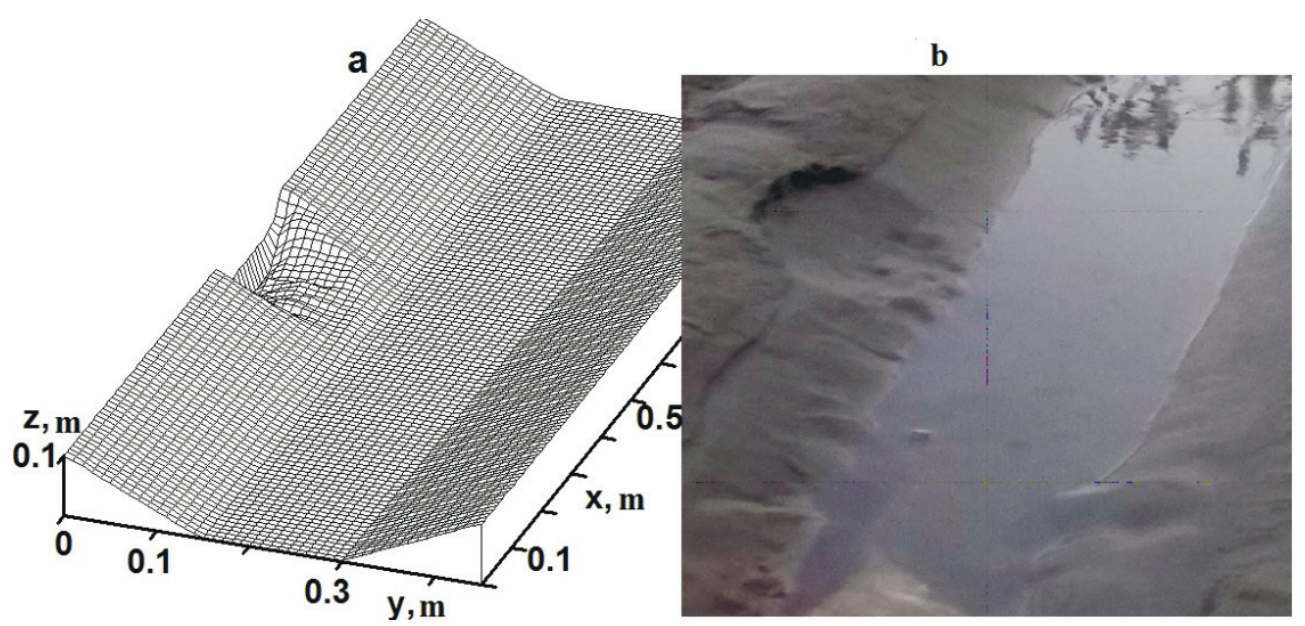

Fig. 2. The surface of the drained channel (a) calculated by the model and (b) its photo.

\section{Mathematical model}

The mathematical model consists of a hydrodynamic, heat, and deformation modules. The major model equations are described in [12]. The new interpretation considered here can take into account variations in ice content of frozen inclusions. In addition to changes in the position of the surface in contact with water, the model takes into account variations in the positions of surfaces at the boundary with warm soil. In the calculation of the position of the water-ice/frozen soil boundary, the Stefan condition is modified by adding an advection 
term, which accounts for the transport of thawed-material particles by water flow, as it has been done in the model $[15,16]$ :

$$
h\left(T_{w}-T_{m}\right)=\rho L \frac{\partial s}{\partial t}-k\left(\frac{\partial T}{\partial x}\right)_{x=s} \quad x=s(t)
$$

Where $s(t)$ is the instantaneous position of the interface, $T_{w}$ is water temperature, $T_{m}$ is ice melting temperature, $k, \rho, L$ are the heat conductance, density, and the latent heat of thawing of the frozen sample. The heat conductance $h$ between the turbulent water flow and the frozen sample can be found from the relationship $h=N u \frac{k_{w}}{L_{c a r}}$, where $k_{w}$ is water thermal conductivity; $L_{\text {char }}$ is characteristic scale, $\mathrm{Nu}$ is Nusselt number, calculated using the empirical formula $N u=\operatorname{Pr}^{\alpha} \operatorname{Re}^{\beta} A$, where $\operatorname{Pr}$ is Prandtl number, varying from 13 to 7 as water temperature rises from $0^{\circ} \mathrm{C}$ to $20^{\circ} \mathrm{C}, R e=\frac{L_{c a r} V_{w}}{v_{w}}$ is Reynolds number, $V_{w}, v_{w}$ are water velocity and kinematic viscosity, respectively. The empirical coefficients, as well as in [14], were taken as follows: $A=0.003031, \alpha=0.3333, \beta=1.1211$.

\section{Results and discussion}

The main objective of the study was to assess the significance of the factors involved in the process of river channel deformations in the permafrost zone, including separation of frozen particles through thawing and their transport by water flow, i.e., ablation, described by heat conductance equation and a modified Stefan condition (1); sediment transport induced by disturbance of flow homogeneity by thawed domains; collapses of bank slope, which loses the skeleton it has had in the form of frozen soil and becomes unstable as its natural equilibrium slope drops below the actual slope. The model was verified against the results of preliminary calculations for short time intervals (up to $15 \mathrm{~min}$ ) with the comparison of the obtained results with laboratory experiments for the case of ablation alone [17]. The difference between averaged deformations calculated by a pure-ablation model, i.e., not taking into account collapses and sediment transport, and the full model reached $20 \%$. In the simulation over longer periods, the difference increases, as can be seen from Fig. 3, which gives time variations of the averaged deformations, calculated by different variants of the model, and cross-sections of the channel, calculated for the section passing through the center of the plate $60 \mathrm{~min}$ after its placing into the bank slope for the same model variants.

Clearly, the values of deformations calculated with no account taken of sediment transport and collapses are much higher than the values obtained from the full model. 

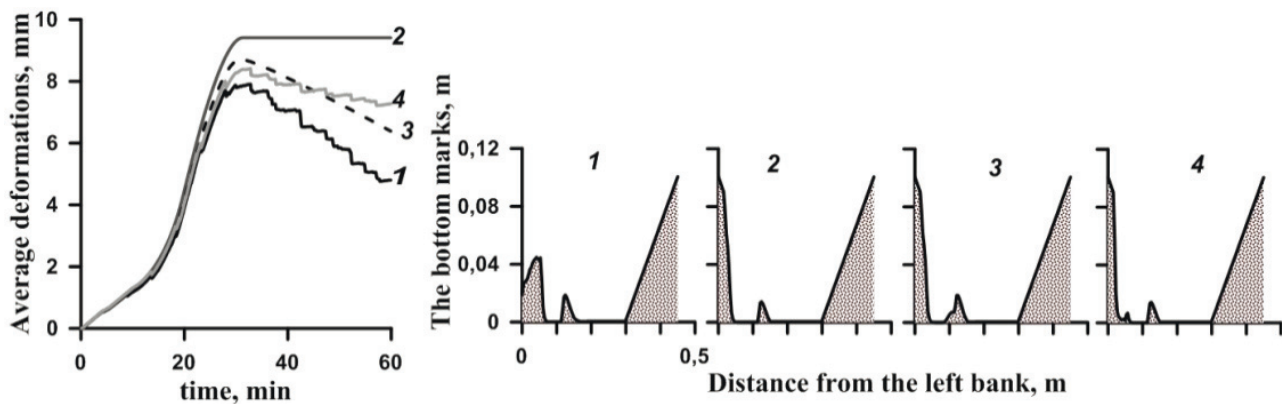

Fig. 3. Time variations of (a) the averaged deformation sand (b) cross sections of the channel, in the middle of the plate $60 \mathrm{~min}$ after its placement in the coastal slope, calculated by different versions of the model: (1) full model, (2) pure ablation model (without sediment transfer and collapse), (3) excluding collapse (ablation + sediment transfer), (4) excluding sediment transfer (ablation + collapse).

\section{Conclusions}

Numerical experiments carried out with the use of a modified mathematical model of full deformations over long time intervals showed that the difference between averaged deformations calculated by the model of pure ablation, i.e., with no account taken of collapses and sediment transport, and the full model, can increase. In this case, the values of deformations calculated with sediment transport and collapses not taken into account are far in excess of the values calculated by the full model. This result is in agreement with the data of experiments with a flume.

At the averaging over channel segments longer than the size of ice inclusions, the average values of deformations can slightly differ when calculated by the full deformation model or the model of pure ablation; however, the values of maximal (accumulation) and minimal (erosion) deviations of the channel surface in the calculations by the full model are far in excess of those calculated by the pure-ablation model. This shows that channel deformations over the space are uneven. Experiments in hydraulic flume were accurate enough to reproduce the effect of delayed collapse, consisting in the nonsimultaneous effects of the thawing of the channel-forming rocks and a freshet.

Mathematical simulation, numerical experiments, and their analyses were supported by the Russian Foundation for Basic Research, projects no. 18-05-00178, 20-08-00807; experimental studies and the processing of their results were carried out under Governmental order no. 0147-2019-0001 (state registration no. AAAA-A18-118022090056-0).

\section{References}

1. A.V. Kotlyakov, I.I. Gritsuk, O.Ya. Maslikova, N.K. Ponomarev, Iceandsnow, 114, 92 ( 2011)

2. L. Dupeyrat, F. Coastard, R. Randriamazaoro, E. Gailhardis, E. Gauter and A. Fedorov, Permafrost and Periglacial Processes, 22, 179 (2011)

3. N.I. Tananaev, Dynamics of gully forms and channel processes, 107 (2002)

4. A. Zaitsev, N.I. Tananaev, Geomorfologiya, 1, 25 (2008)

5. F.E. Are, Proc. of the $4^{\text {th }}$ International Conference on Permafrost, 24 (1983)

6. K. Ballentyne, Periglacial Geomorphology (2018)

7. N. Kobayashi, J. of Geophysical Research, 90, 11983 (1985)

8. N. Kobayashi, J.C. Vidrine, R.B. Nairn, S.Solomon, J. of Coastal Research 15, 332 (1999) 
9. H. Lantuit, P.P. Overduin, N. Couture, R.S. Odegard, Proc. of the $9^{\text {th }}$ International Conference on Permafrost, 1025 (2008)

10.Y. Shur, A.Vasiliev, M. Kanevskiy, V. Maksimov, S. Pokrovsky, V. Zaikanov, Proc. of the 11th Intern. Conf. on Cold Regions Engineering, 736 (2002)

11. E.I. Debol'skaya,Water Resources, 5, 512 (2014)

12. E.I. Debol'skaya, I.I. Gritsuk, V.K. Debol'skii, D.N. Ionov and, O.Ya. Maslikova, Water Resources, 4, 542 (2018)

13. J. Aguirre-Puente, F.Costard, R. Posado-Cano, J. of Geophysical Research, 99, 5657 (1994)

14. F. Coastard, L. Dupeyrat, E. Gautier, E. Carey-Gailhardis, Earth Surf. Process. Landforms, 28, 1349(2003)

15. L. Dupeyrat, R. Randriamazaoro, F. Costard, E. Carey-Gailhardis, Proc. of the Ninth International Conference on Permafrost, 1, 391 (2008)

16. R. Randriamazaoro, L. Dupeyrat, F. Costard and E. Carey-Gailhardis, Earth Surface Processes and Landforms, 32, 1828 (2007)

17. E.I. Debol'skaya, A. V. Ivanov, Water Resources, 1, 77 (2020) 